\title{
Cultura, educação e filosofia na perspectiva Nietzschiana
}

\begin{abstract}
Alex Marques ${ }^{37}$
Resumo: O presente texto se propõe apresentar algumas reflexões acerca dos escritos nietzschianos "Sobre o futuro de nossos estabelecimentos de ensino" (1871) e "Schopenhaver Educador" (1874). As reflexões sobre educação e cultura partem das experiências do filósofo quando ensinava na universidade de Basiléia/Suíça. Segundo este filósofo, para existir cultura é preciso um projeto educativo, pois não haverá educação sem uma cultura que lhe sirva de apoio. Há uma exacerbada valorização de um tipo de saber, busca-se o acumulado em excesso e sem relação com os contextos culturais e sociais dos indivíduos. Nas críticas nietzschianas percebemos uma luta por uma concepção de educação pautada nas experiências vivas de cada indivíduo, pois a vida é percebida como propulsora de diferentes formas de pensar e conhecer. Assim, podemos extrair em Nietzsche ferramentas contrarias a uma cultura de massa destinada a padronização, alienação e competitividade e o ensino de filosofia como uma aliada na denúncia e crítica de nossa sociedade e de seu povo.
\end{abstract}

Palavras chaves: educação; cultura; filosofia.

\section{Culture, Education and philosophy in perspective Nietzschean}

\begin{abstract}
The present text proposes to present some reflections about the Nietzschean Writings "The future of our educational establishments" (1871) and "Schopenhaver Educator" (1874). The reflections about education and culture depart from philosopher experiences when he taught at the University of Basel / Switzerland. According to this philosopher, to exist culture requires an educational project, because there will be no education without a culture that supports it. There is an exacerbated valuation of a type of knowledge, it is sought the accumulated in excess and without relation with the cultural and social contexts of the individuals. In the Nietzschean critics, we perceive a struggle for a conception of education based on the living experiences of each individual, since life is perceived as a propeller of different ways of thinking and knowing. Thus, we can extract in Nietzsche tools contrary to a mass culture destined to standardization, alienation and competitiveness and the teaching of philosophy as an ally in denouncing and criticizing our society and its people.
\end{abstract}

Key words: education; culture; Philosophy.

${ }^{37}$ Mestre em Educação pela Faculdade de Educação da Universidade Federal da Bahia (UFBA). Licenciado em Filosofia pela Universidade Federal do Recôncavo da Bahia (UFRB). Professor da Faculdade da Cidade do Salvador nos cursos de Docência do Ensino Superior e Psicopedagogia com experiências na formação de professores e ensino de Filosofia. E-mail: amarques89@hotmail.com 


\section{Introdução}

Neste texto se estruturam dois momentos: primeiro buscamos compreender como estrutura a análise realizada pelo filósofo Nietzsche no que diz respeito aos estabelecimentos de ensino alemães e que em muito se aproxima de nossa realidade brasileira; e um segundo momento, a partir de seu contato com as leituras das obras do filósofo Schopenhaver, Nietzsche mostrará os perigos, as dificuldades e as peculiaridades da experiência formativa a que se é submetido na presença de um filósofo intempestivo.

Entraremos em um labirinto no qual os minotauros são monstros que necessitamos domá-los, sejam eles a decadência de um sistema educacional sendo devorado pelas investidas de um poder estatal e econômico, seja por uma compreensão de ciência e uma formação (instrução) que não favorece um modo criativo de ser e da potencialização da vida. O que será possível ver é que tais labirintos, aparentemente confusos e cheios de direções, contribuem para traçar coordenadas na cartografia das críticas Nietzschianas à educação de sua época.

É necessário que ao buscarmos compreender as análises do filósofo intempestivo, possamos segurarmos no fio condutor de um novelo de questões que devem surgir à mente ao adentrar em seu labirinto. Entre caminhos e paisagens nos interrogamos: Como as análises, aqui levantadas, se aproximam de nossa realidade e contexto, já que não somos alemães, nem gregos e cuja "elevação" espiritual geralmente passa pelos altares de algum templo (WEBER, 2008) - e essa é a nossa raiz, com todas as possibilidades e contradições de misturas de crenças, estilos e línguas - e não por uma tradição constituída de reflexões sobre filosofia, literatura, educação?

Acreditamos que tais questões não nos são completamente estranhas, pois aquilo que está na raiz do problema da educação, da formação (bildung), da cultura, diz respeito a qualquer cultura e a qualquer ser humano, pois é necessário que se pense o sentido de ser humano a partir do seu estar no mundo. 


\section{Educação e cultura: apontamentos necessários}

A educação e a cultura, para Nietzsche, são inseparáveis, ou seja, para existir cultura é preciso um projeto educativo, pois não haverá educação sem uma cultura que a sustente. Esta perspectiva nos ajuda a compreender o processo de decadência a que chegará os estabelecimentos de ensino e a educação ministrada nas instituições de ensino da Alemanha do século XIX, produzindo um ensino pelo acúmulo excessivo de conhecimento desvinculado da vida. A educação ministrada no solo alemão, segundo Nietzsche, representava um sistema educacional que abandonara a formação humanista em proveito de uma formação cientificista.

A consequente vulgarização do ensino tinha por objetivo formar homens úteis e rentáveis, e não personalidades harmoniosamente desenvolvidas, inventivas e amadurecidas. A respeito dessa decadência pedagógica que chegara a escola, assevera Nietzsche:

E, no entanto, em lugar nenhum se chega à sinceridade total; a triste causa disso é a pobreza de espírito pedagógico de nossa época; eis que estão ausentes justamente os talentos realmente inventivos, eis que faltam os homens práticos, quer dizer, aqueles que têm ideias boas e novas e que sabem que a verdadeira genialidade e a prática correta devem necessariamente encontrar-se no mesmo indivíduo: embora os práticos prosaicos faltem justamente às ideias e, por esta razão, também a prática correta (NIETZSCHE, 2009, p. 79).

No texto inacabado das conferências intituladas "Sobre o futuro dos nossos estabelecimentos de ensino" (1872), Nietzsche apresenta algumas reflexões sobre a educação ministrada no gymnasium, ${ }^{38}$ nas escolas técnicas e nas universidades. Como explica Sobrinho (2009, p, 110) "Há nestas conferências apontamentos de métodos, conteúdos, objetivos e as formas de educação dos jovens bem como as relações didáticas entre professor e

${ }^{38}$ Equivalente em nosso currículo à Educação Básica. A Educação Básica equivale hoje em três etapas: Infantil, Fundamental e Médio. O fundamental do $6^{\circ}$ ao $9^{\circ}$ ano. $\mathrm{E}$ o ensino médio em três anos.

Revista Digital de Ensino de Filosofia - Santa Maria - vol.2., n.2 - jul./dez. 2016. 
aluno". Essas críticas evidenciam a preocupação do filósofo diante do enfraquecimento da cultura alemã, devido ao processo de fragmentação, no qual a cultura não pode ser percebida como algo dissociado da natureza, já que é por ela que a cultura é determinada. Porém, a educação nestes estabelecimentos de ensino dissocia as experiências vivas de cada estudante em prol de um conhecimento apenas teórico, a este respeito nos diz Rosa Dias:

Todo sistema educacional é concebido como se o jovem pudesse descobrir sua vida nas técnicas passadas. Como se a vida não fosse um ofício que é preciso aprender a fundo. Quem quiser pulverizar esse tipo de educação deveria, segundo Nietzsche, ser o porta-voz da juventude, iluminá-la com uma nova concepção de educação e cultura. (DIAS, 1993, p. 64).

Assim, a modernidade apresenta para Nietzsche mediocridade e barbárie, e no âmbito da educação promovia um estudante destituído de uma reflexão entre as questões filosóficas ligadas ao sentido da existência, alimentando assim um sentimento de conformismo e adequação. O Saber teórico acumulado em excesso pelo homem deixa de ser atuante como uma força transformadora. Pois, o que está em pauta para esta formação que busca ajustar os indivíduos às estruturas existentes, é a formação de um homem teórico que busca priorizar o intelecto como algo dissociado da própria vida, estabelecendo assim uma ruptura entre vida e pensamento, corpo e inteligência. Neste sentido, nos diz Rosa Dias (1993):

\footnotetext{
Nietzsche despreza o sistema educacional que tem sob seus olhos. Esse sistema visa promover o "homem teórico", que domina a vida pelo intelecto, separa vida e pensamento, corpo e inteligência. Em lugar de procurar o conhecimento a serviço de uma melhor forma de vida, coloca-o em função de si próprio, de criar mais saber, independentemente do que isso possa significar para a vida (DIAS. 1993, p. 32).
}

O sistema educacional em prática nas instituições da Alemanha, para 
Nietzsche, estimula uma erudição livresca destituída de qualquer atenção para uma formação humanística, sua função é produzir estudantes especializados em profissões para uma vida de sobrevivência. A figura do erudito passa a ser a moda do momento, em seu interior há o "acúmulo de saber" e uma pressa em chegar a todo custo à certeza e a verdade. 0 excesso de história, a cultura livresca, a separação do corpo e do espírito, segundo Rosa Dias, levam Nietzsche a dizer que a Alemanha não tem exatamente uma cultura. Se de fato existe, ela é artificial e não a expressão direta da vida: um suplemento, um excedente.

Com seu olhar singular para as questões da educação, Nietzsche busca uma concepção de educação pautada nas experiências vivas de cada indivíduo, pois, a partir das leituras das tragédias a vida é percebida como propulsora de diferentes formas de pensar e conhecer. Seria necessário, segundo Nietzsche (Cf. 2009, p. 81), educar-se a si mesmo e contra si mesmo. Ou seja, formar novos hábitos e uma nova natureza e assim se desfazer novamente de nossa primeira natureza em um processo de metamorfose constante.

\section{A ampliação e redução máxima da cultura}

A palavra cultura na sua origem etimológica é oriunda do verbo latino colere significando o cultivo, o cuidado. Inicialmente podemos pensar a cultura como um modo de vida, de pensamento ou como campo próprio instituído pela ação humana referente a todos os aspectos da vida social. Etimologicamente a palavra cultura dimensiona para a natureza, a "lavoura", "cultivo agrícola" que entrelaça um movimento tanto de um crescimento espontâneo como movimento regulado, elaborado. Segundo Chauí (2008) ligada ao cultivo e ao cuidado com a terra, nos dá a noção de agricultura, já o cuidado com as crianças, denomina-se puericultura. Com os deuses e o sagrado, surge o "culto" que no latim, refere-se o termo cultus, compreendendo tanto o sentido religioso quanto aos cuidados com os pertences. Como cultivo, a cultura era concebida como uma ação que conduziria a plena realização das potencialidades de alguma coisa ou de alguém. 
Segundo Chauí (2008, p. 55) no correr da história do ocidente, no século XVIII, a palavra cultura ressurge, porém como sinônimo de civilização. Civilização deriva-se da ideia de vida civil, portanto, de vida política e de regime político. Com o movimento lluminista a cultura passa a ser vista como o "padrão" ou o "critério" que mede o grau de civilização de uma sociedade. A noção de tempo contínuo, linear e evolutivo, segundo Chauí (2008), é introduzida no conceito de cultura, o que pouco a pouco a torna sinônimo de progresso. Neste sentido, o progresso de uma civilização seria avaliado pela sua cultura e assim se avaliaria a cultura pelo progresso que esta traz a uma civilização.

As sociedades modernas passaram a ser avaliadas segundo a ausência ou presença de alguns elementos, os quais são próprios do ocidente capitalista e a ausência desses elementos era considerada sinal de falta de cultura ou de uma cultura pouco evoluída. Segundo a filósofa Chauí, os elementos que passam a ser critério de avaliação das sociedades são: "o Estado, o mercado e a escrita. Todas as sociedades que desenvolvessem formas de troca, comunicação e poder diferentes do mercado, da escrita e do Estado europeu, foram definidas como culturas "primitivas" (CHAUÍ, 2008 p. 56).

A cultura não é estática pois é sempre uma tensão entre aquilo que é racional e espontâneo. Não sendo determinada e fixa, muito menos deliberadamente modificada, ela implica aquilo que a natureza realiza em nós, a saber, as ações que realizamos na natureza. A cultura é um movimento oriundo de seu próprio processo vital. Neste sentido, é necessário compreendermos que sobre o conceito de cultura, na raiz de toda significação, há forças, isto é, todos os eventos significativos são movidos pela junção de significado e de poder, por sua vez, só podem ser identificados a partir da própria cultura.

Mas, qual é a definição de cultura em Nietzsche? O filósofo, no livro David Strau: o devoto e o escritor, nos dá uma definição daquilo que ele define como cultura:

A cultura é antes de mais nada uma unidade de estilo que se manifesta em todas as atividades de uma nação. Mas saber muito e ter aprendido 
muito não são nem meio necessário nem um signo de cultura, mas combina perfeitamente com o contrário de cultura, a barbárie, com a ausência, com ausência de estilo, ou com a mistura caótica de todos os estilos (DE, §2, p. 11).

O filósofo compreende cultura como arte, criação diferente de algo que se possa adquirir ou possuir. A cultura, para Nietzsche, deveria possibilitar a criação dos grandes gênios, dos seres criadores e inventivos. É justamente pela distinção entre o tempo da lentidão e o tempo da pressa que os conceitos de "cultura autêntica" e "pseudocultura", tão presentes na escrita nietzschiana podem ser estabelecidos.

É preciso elucidarmos que muitas expressões utilizadas por Nietzsche podem soar estranhas ou se julgadas por algum cunho ideológico levaria a um viés justificador de concepções extremistas. Sendo um filósofo intempestivo e crítico do seu tempo, Nietzsche ao falar de cultura, tal qual ele compreende, a cultura autêntica, é aquela que não está presa a um fim utilitário e pragmático. A cultura não pode estar a serviço do desenvolvimento de aptidões utilitárias, sejam questões políticas, militares ou formação profissional, isto inviabilizaria o desenvolvimento da própria cultura na concepção nietzschiana.

Nietzsche entende por cultura autêntica ou verdadeira cultura aquela que permite ao homem aceder ao seu próprio ser criador. A cultura, neste sentido, não pode estar a serviço de bens materiais ou o desenvolvimento de aptidões utilitárias. Este tipo de cultura exige muitas renúncias, trabalho e restrições a poucas coisas e autodomínio, pois são habilidades adquiridas lentamente, que "só tem início numa atmosfera que está acima deste mundo das necessidades, da luta pela existência, da miséria" (EE. §III, p.103).

Ao propor uma restauração na cultura alemã, Nietzsche examina as instituições de ensino responsáveis por administrar as diferentes etapas de formação dos jovens. O ginásio, a escola técnica e a universidade demonstram a decadência de uma cultura apressada e uma formação rápida destituída de concisão e rigor. Neste sentido, Nietzsche inicia suas críticas ao ginásio, pois, é neste ambiente que irá refletir as fases posteriores de aprendizado de uma renovação cultural. 
Nas conferências escritas em 1872, Nietzsche (2009, p, 72) aponta ao público algumas tendências que desgastam a educação e estendem seus efeitos negativos à cultura. A tendência à extensão, à ampliação da cultura, e a tendência à redução, ao enfraquecimento da própria cultura. A primeira, a tendência de ampliação máxima, busca estender o direito da cultura e acessibilidade a todos, porém para isto, seria necessário estar vinculada à economia política, que segundo Nietzsche, estava ligada aos interesses do mercado.

Ligada ao lucro e à utilidade, a tendência à ampliação buscaria promover um indivíduo da utilidade e do acúmulo de conhecimento, estando assim permeado pela produção em larga escala, segundo as necessidades vigentes. A finalidade desta tendência é a produção em série, tanto de bens como de homens correntes. O lucro e felicidade aqui se equivalem para este homem que tem a vida como um valor a ser produzido em fábrica. Com tom irônico, acerca da tarefa que exerce a concepção de ampliação da cultura, nos diz Nietzsche:

\begin{abstract}
A verdadeira tarefa da cultura seria criar homens tão 'correntes' quanto possível, um pouco no sentido em que se fala de uma 'moeda corrente'. Quanto mais houvesse homens correntes, mais um povo seria feliz; e o propósito das instituições de ensino contemporâneas só poderia ser justamente 0 de fazer progredir cada um até onde sua natureza o conclama a se tornar 'corrente', formar os indivíduos de tal modo que, do seu nível de conhecimento e de saber, ele possa extrair a maior quantidade possível de felicidade e lucro (NIETZSCHE, 2009, p. 73).
\end{abstract}

Percebe-se que a cultura, ligada à tendência de ampliação e aos interesses da economia política, descaracterizava o indivíduo singular e diferente. É preciso, segundo esta concepção, uma cultura que tenha como fim o lucro baseado em uma "cultura rápida". Seu fundamento está vinculado ao interesse do Estado em investir na formação de seus funcionários e de seus exércitos para melhor se capacitar na luta contra outros Estados.

Chegamos assim à segunda tendência que desgasta a cultura: a redução. Nesta tendência de redução, os indivíduos deveriam trabalhar em consonância com a defesa dos interesses ligados ao Estado, sendo servidores Revista Digital de Ensino de Filosofia - Santa Maria - vol.2., n.2 - jul./dez. 2016. 
que, pautados em uma especialização e formação rápida, deixariam de lado a "fidelidade nas pequenas coisas", ou seja, no trato e na disciplina com as questões e tarefas que envolvam a cultura e seu desenvolvimento. Esta tendência prega a divisão do trabalho nas ciências e a especialização do erudito em determinada área.

É importante entendermos que o erudito é o intelectual movido por um paradoxo: de um lado tem-se o instinto de conhecimento e do outro uma imensa pressa do conhecimento. Também é destituído de uma visão abrangente e realista no que diz respeito à vida e ao mundo. Seu campo de visão é estreito, são produtivos no sentido quantitativo e o excesso de conhecimento lhes pesa o ombro, o tédio lhes é nocivo e assim se "arrastam no estado de espírito morno ou gélido no qual realizam suas tarefas diárias" (NIETZSCHE, 2009, p. 229). Este homem é, para Nietzsche, explorado em proveito da ciência como uma espécie de vampiro, extrai de tudo e de nada absorve com profundidade. ${ }^{39}$ Sendo a ciência e 0 homem teórico participantes da divisão do trabalho, ambos visam a redução e o aniquilamento da própria cultura.

\section{O filósofo e o professor de filosofia: o exemplo Schopenhaver}

Schopenhaver foi um filósofo solitário que nutria pouco interesse por castas acadêmicas e manteve sua busca de independência do Estado e da sociedade. O isolamento e o "desprezo da verdade", segundo Nietzsche, são alguns sentimentos causadores de uma série de mal-entendidos frente ao filósofo. É fruto a filosofia oferecer ao "homem um asilo onde nenhum tirano pode penetrar, a caverna da interioridade, o labirinto do coração: e isto deixa enfurecidos os tiranos" (SE, §2 p. 181).

Para além de uma vida conformada com sua época, Schopenhaver segundo Nietzsche, levantou-se contra sua cultura, expulsando de si e tornando-se um filho bastardo de caráter intempestivo e nunca de conformidade. Viveu sem temer entrar em contradição com a ordem

39Segundo Rosa Maria Dias, a concepção de Nietzsche acerca da ciência alteram-se ao longo de sua obra. Entre os períodos de 1870 a 1876, a ciência é vista como saber que destrói as ilusões em proveito da sobrevivência dos homens.

Revista Digital de Ensino de Filosofia - Santa Maria - vol.2., n.2 - jul./dez. 2016. 
existente, e sentiu em si o "pulsar do gênio". São estes os exemplos que Nietzsche tira de Schopenhaver para compreender o que há de mais exemplar e educador na natureza deste filósofo. Percebemos que ao explicitar tais caraterísticas da figura de Schopenhaver, Nietzsche tenta extrair os impulsos e as forças vitais que impulsionaram este educador. Seria tarefa dos jovens ligar-se a algum grande homem, vendo-o como um ser que se elevou e reconhecer humildemente sua estreiteza diante da grandeza do gênio. Mas como encontrar em uma cultura que está em decadência estes exemplares que sirvam de modelo? Será que as instituições de ensino possibilitam o nascimento de tais seres intempestivos?

Nietzsche percebe que nas instituições de ensino superior o filósofo como educador é algo abjeto, pois nestes ambientes misturam-se a seriedade da filosofia com a mesma seriedade da cultura do jornal, tudo é transformado em uma pressa indecorosa. O Estado é colocado como bem supremo da finalidade última, sendo o homem destinado ao seu serviço. Ao recorrer a imagem de Schopenhaver, Nietzsche pergunta-se como o filósofo vê a cultura de sua época. É inevitável perceber que toda falta de simplicidade, de recolhimento e lentidão para o exercício filosófico são descaracterizadas para a segurança em carreiras, honras, e prestígio, pois estes são "sintomas de uma extirpação e de um desenraizamento completo da cultura" (SE, §4, p. 193).

Neste cenário de total "cultura artificial" é preciso estabelecer as diferenças entre os filósofos e os professores de filosofia, em meio a uma época que há um endeusamento do Estado como finalidade última de bem-estar, e a filosofia é vista como instrumento de ganha pão. Neste sentido, Nietzsche, influenciado pelas leituras do ensaio de Schopenhaver Sobre a filosofia universitária (1851), conclui que não existem filósofos na universidade, mas apenas professores de filosofia (eruditos) satisfeitos e submissos ao poder econômico do Estado em que vivem.

Para Nietzsche, o Estado tem receio do filósofo, por este ser solitário e de ideias próprias poderá colocar em perigo a permanência do sistema. Por isso, ao favorecer um número grande de filósofos, o Estado busca conferir a ilusão de ter a filosofia ao seu lado. De tal modo, para lecionar o filósofo universitário é obrigado a ensinar as doutrinas que o Estado impõe e que julga ser necessárias à sua existência e tudo que exige como seu bem, por exemplo, Revista Digital de Ensino de Filosofia - Santa Maria - vol.2., n.2 - jul./dez. 2016. 
"uma forma determinada de religião, de ordem social, de organização militar" (SE, §8 p. 246). Percebe-se o adestramento do pensamento pela sua submissão às obrigações trabalhistas. A forte relação entre o pensamento e o controle do Estado sugere a submissão do pensamento ao próprio Estado desempenhando a função de controle total e a atividade universitária descaracterizada da liberdade de investigação.

O Estado na compreensão nietzschiana coloca em perigo o futuro da filosofia, pois é ele que escolhe para si seus "servidores filosóficos", na medida em que preenche seus quadros institucionais e decide aos seus critérios aqueles que são bons ou maus filósofos. O filósofo profissional ou professor de filosofia é, antes de qualquer coisa, um funcionário. É preciso que o professor de filosofia se torne pouco a pouco um mestre na erudição e não mais um pensador, pois sua tarefa é ser um historiador da filosofia e assim, "refletir sobre o pensamento de outro e repeti-lo" para ter sempre algo a dizer aos seus alunos.

Porém, o professor de filosofia exercendo sua função que the é imposta pela necessidade estatal conseguirá pensar com hora marcada? Estará pensando quando o que pensa contraria os princípios do Estado, seu patrão? No texto da primeira conferência, Nietzsche nos diz o seguinte: "Como? Vocês temem que o filósofo os impeçam de filosofar? Eis que isto pode mesmo ocorrer, e vocês não o experimentaram ainda? Não tiveram a experiência disso na Universidade? Não ouviram, enfim, aulas de Filosofia?" (EE,§l, p. 57).

O esquema acadêmico a partir das influências do Estado é tão bem estruturado que nenhum professor sente falta do que dizer, pois nem professores e nem estudantes pensam por si mesmos ${ }^{40}$. Todas as lacunas que existem no sistema universitário, nesta organização, são supridas pela cultura histórica e científica. Segundo Nietzsche, esta é uma concessão perigosa que o filósofo faz ao Estado, pois se torna um erudito e historiador da filosofia ${ }^{41}$.

\footnotetext{
${ }^{40}$ Cf. DIAS, 1993, p. 107.

${ }^{41}$ Nietzsche não descaracteriza o estudo da história, apenas busca pensá-la enquanto possibilidade de entender as grandes construções humanas, artes, arquiteturas e como possibilidade de conhecer mundos. O problema é fazer da história o único saber verídico e, assim, deixar de lado as novas construções sem perceber o que brota do novo, a vida em seu momento presente gerando também novos aprendizados e vivificando o saber. Diz Nietzsche: "A história erudita do passado jamais foi o afazer de um verdadeiro filósofo, nem na Índia, nem na Grécia; e um professor de filosofia, Revista Digital de Ensino de Filosofia - Santa Maria - vol.2., n.2 - jul./dez. 2016.
} 
Neste sentido, dirá o filósofo:

E afinal de contas, o que importa a nossos jovens a história da filosofia? Devem eles ser desencorajados a ter opiniões, diante do montão confuso de todas as que existem? Devem eles também ser ensinados a entoar cantos jubilosos pelo muito que já tão magnificamente construímos? Devem eles porventura aprender a odiar e desprezar a filosofia? [...] E agora, que se imagine uma mente juvenil, sem muita experiência de vida em que são encerrados confusamente cinquenta sistemas reduzidos a fórmulas e cinquenta críticas destes sistemas que desordem, que barbárie, que escárnio quando se trata da educação para a filosofia! (SE, §8, p. 248).

Em função de uma massa de conhecimentos que precisa ser administrada pela universidade, o jovem, segundo Nietzsche, não é educado para pensar e viver filosoficamente, tendo como meta a assimilação de conhecimentos que possam ser "despejados" na prova de filosofia. É preciso adestrar $^{42}$ a compulsão de saber, pois o ensino acaba desencorajando o jovem a ter opiniões próprias, em função de todo conhecimento histórico que é preciso assimilar ${ }^{43}$. Neste sentido a prerrogativa nietzschiana defende a necessidade da filosofia se desvincular do Estado para que este não continue intervindo e dirigindo este conhecimento ao seu favor ${ }^{44}$.

Nietzsche percebera que não há um vínculo entre o pensamento e a vida em sua sociedade, pois o que há é "uma grande miopia para o longínquo e geral" (SE, §6, p. 225). A vida é tratada a partir de um pensamento

quando está ocupado com um trabalho desse gênero, deve se contentar com que se diga dele, no melhor dos casos: 'É um bom filólogo, um bom especialista dos antigos, um bom linguista, um bom historiador'- mas nunca: 'É um filósofo. '” (SE.§8, p. 248). ${ }_{42} \mathrm{O}$ adestramento, ao qual Nietzsche se refere, busca adestrar o que há de animalidade no homem, ou seja, seus instintos. Nietzsche refere-se à busca incessante do homem - o desejo de conhecimento - como um instinto. Os instintos precisam ser educados e disciplinados e não negá-los ou reprimi-los como ocorre com uma educação decadente. Sobre adestramento em Nietzsche ver: Rosa Dias, Nietzsche, vida como obra de arte, 2011.

${ }^{43}$ Cf. DIAS, 1993, p. 108

${ }^{44}$ Contrário a este pressuposto, segundo Silvio Gallo (2012), um exemplo nefasto que tivemos em nossa realidade brasileira foi retirada de alguns conhecimentos, entre eles a filosofia, sociologia e artes do currículo escolar pelo próprio Estado no período da Ditadura Militar.

Revista Digital de Ensino de Filosofia - Santa Maria - vol.2., n.2 - jul./dez. 2016. 
datado, histórico, ao qual é ensinada apenas "a crítica pelas palavras" e não o estímulo a experimentar e viver de acordo a filosofia.

É importante percebermos que a "força" extraída de Schopenhaver como "ideal que educa" a partir de seu exemplo intempestivo, levará Nietzsche a elaborar seu próprio processo de formação e sua concepção de educação. Pautada nas experiências vivas, relacionadas com um pensamento grandioso que não se conforma com sua época, crítica, cria e tem na vida a vontade de potência ${ }^{45}$.

\section{Conclusão}

Entendemos que Nietzsche não é contrário à proliferação na Alemanha de escolas com ensino técnico. O filósofo não descarta a possibilidade de criação de escolas técnicas, às quais são destinadas a uma educação para a sobrevivência. Pois, é nestes ambientes que os estudantes aprendem a dominar a linguagem para a comunicação, a calcular corretamente e adquirem conhecimentos das ciências naturais.

As escolas cumprem com seus objetivos formar negociantes, médicos e funcionários oficiais. Porém o ginásio e a universidade em suas diretrizes, segundo Nietzsche, continuam a acreditar que são lugares onde a cultura ainda é alimentada. Para Nietzsche, estas duas instituições, em seus objetivos, não se distinguem das escolas destinadas apenas a instrumentalização técnica. Segundo Rosa Dias (1993):

O que Nietzsche censura, ao afirmar que a cultura é "serva do ganha-pão e da necessidade", é o fato de o gymnasium e a universidade se terem voltado para a profissionalização e, apesar disso, continuarem a acreditar que são lugares destinados a cultura, quando na verdade não se distinguem muito da escola técnica em seus objetivos (DIAS, 1993, p. 99).

Para Nietzsche, não há existência de cultura sem o desligamento do

45 De modo geral a vida como vontade de potência busca sempre ampliar-se, apropriar e criar novas condições e como este movimento contínuo das forças possibilita estímulos que intensifica corpo e pensamento, ou seja, a experimentação. Revista Digital de Ensino de Filosofia - Santa Maria - vol.2., n.2 - jul./dez. 2016. 
"mundo das necessidades". O homem ligado a este mundo da luta individual pela vida não poderá dispor de tempo suficiente para atingir uma verdadeira cultura. O ginásio deixara de alimentar a verdadeira cultura, ou seja, a cultura aristocrática, a qual busca a nutrição e o engendramento do gênio. ${ }^{46} \mathrm{O}$ gênio é uma natureza solitária no mundo, contemplativa e de criações eternas, a exemplo de Beethoven, Schiller, Goethe, Schopenhaver e tantos outros. Conforme explica Dias (1993, p. 81), "a extensão da alma, a força da imaginação, a atividade do espírito, a abundância e a irregularidade das emoções - tudo isso compõem o caráter do gênio".

O nascimento do gênio não depende da cultura, pois ele é uma dádiva da própria natureza, porém a sua nutrição e amadurecimento se dão em meio ao seio materno da cultura de um povo. Neste sentido é que o ginásio, para Nietzsche, deve ser fecundo ao promover uma educação e cultura que requer a auto-superação da grande individualidade a partir da autocrítica. É preciso lentidão no pensar, experiência interior com o pensamento solitário e criador, o qual exige um tempo de maturação.

Neste sentido, a natureza, segundo Nietzsche, produz um número extremamente limitado de homens para a cultura, havendo necessidade estabelecimentos de ensino preocupados com este tipo de formação. Contudo, temos o movimento contrário, surgem inúmeros estabelecimento de ensino onde reina uma cultura de massa sem o olhar cuidadoso da qualidade, políticas de acesso e permanência.

Neste sentido, as reflexões aqui apresentadas buscam na interpretação nietzschiana promover uma ideia de cultura e educação que prolongue a natureza a realizar sempre a sua obra: a formação de indivíduos que saibam lidar com a vida e o pensamento de forma a criar e recriar incessantemente. Uma concepção de educação que desenvolva nos estudantes a personalidade ativa e criadora frente a sociedade em que se encontra.

Em uma época de massificação e padronização, faltam indivíduos que saibam lidar com as inseguranças, os conflitos e suas subjetividades. Contra a massificação cultural podemos extrair em Nietzsche e tantos outros autores e filósofos ferramentas contraria a uma cultura de massa destinada a

46 Nosso propósito não é abordar a teoria do gênio em Nietzsche, mas apenas explicitar o que é interessante para a compreensão da educação e da cultura.

Revista Digital de Ensino de Filosofia - Santa Maria - vol.2., n.2 - jul./dez. 2016. 
padronização, alienação e competitividade e o ensino de filosofia como uma aliada na denúncia e crítica de nossa sociedade e de seu povo.

\section{Referências}

CHAUÍ, Marilena. Cultura e democracia .En: Crítica y emancipación: Revista latino americana de Ciencias Sociales. Añol, no. 1 (jun. 2008- ). Buenos Aires: CLACSO, 2008.

DIAS, R. M. Nietzsche educador. $2^{a}$ ed. São Paulo: Scipione, 1993.

Civilização Brasileira, 2011.

Nietzsche, vida como obra de arte. Rio de Janeiro:

GALLO, Silvio. Governamentalidade democrática e ensino de Filosofia no Brasil contemporâneo In: Cad. Pesquisa. vol.42 n.145 São Paulo Jan./Apr. 2012

MARTON, Scarlet. Nietzsche: a transvaloração dos valores. $2^{a}$ ed. São Paulo: Moderna, 2006.

NIETZSCHE, F. W. Além do bem e do mal: prelúdio a uma filosofia do futuro. Tradução: P. C. Souza. $2^{a}$ ed. São Paulo: Companhia das Letras, 1992.

O nascimento da tragédia ou helenismo e pessimismo; tradução, notas e posfácio: J. Guinsburg. São Paulo: Companhia das Letras, 1992.

A Gaia ciência. Tradução: J. J. Faria. - São Paulo: Centauro,

2004.

de Janeiro: Vozes, 2008.

Aurora. Tradução: Mário D. Ferreira Santos - Petrópolis: Rio

Crepúsculo dos ídolos ou como se filosofa com o martelo.

Tradução: Edson Bini, Márcio Puglies. - Hemus livraria, São Paulo [200?].

Ecce Homo: como alguém se torna o que se é. Tradução:

P. C. Souza. São Paulo: Companhia das Letras, 2008.

Sobre o futuro de nossos estabelecimentos de ensino. In: Escritos sobre Educação. Tradução: N. C. M. Sobrinho. $4^{a}$ ed., Rio de Janeiro: PUC; São Paulo: ed. Loyola, 2009.

Sobre verdade e mentira no sentido extramoral. Trad. Helga Hoock Quadrado, Lisboa: Relógios D'Água, 1997.

III Consideração intempestiva: Schopenhaver como educador. In: Escritos sobre Educação. Tradução: N. C. M. Sobrinho. 4a ed., Rio de Janeiro: PUC; São Paulo: ed. Loyola, 2009.

SOBRINHO, Noéli, C, M. Apresentação: a pedagogia em Nietzsche in: Escritos sobre Educação. Tradução: N. C. M. Sobrinho. $4^{a}$ ed., Rio de Janeiro: PUC; São Paulo: ed. Loyola, 2009.

WEBER, José Fernandes. Formação (Bildung), Educação e Experimentação: sobre as tipologias pedagógicas em Nietzsche.2008. 172 f. Tese (doutorado em Educação) Universidade Estadual de Campinas, Campinas, 2008. 